\title{
A Tribute to Dr. A. P. Majumadar
}

\section{K. S. Gopinath ${ }^{1}$}

Published online: 23 September 2015

(C) Indian Association of Surgical Oncology 2015

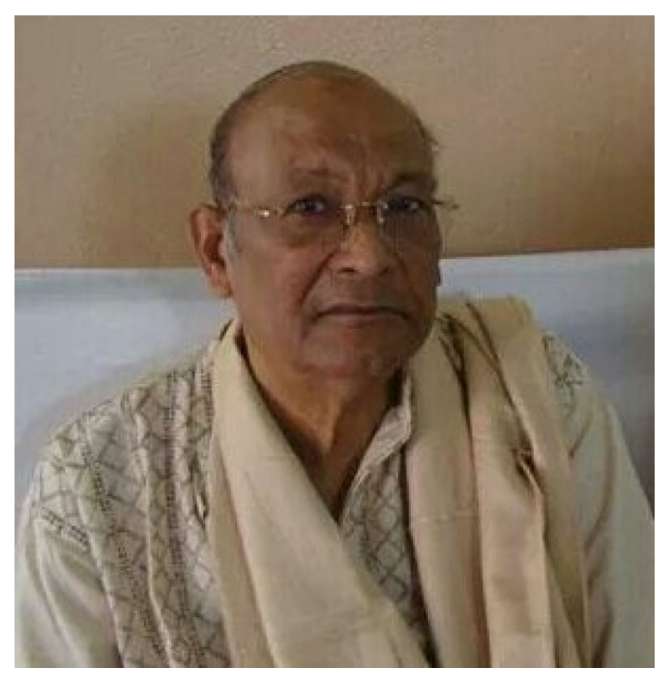

This issue Vol. 6 Issue 3 is dedicated to our past president and founder member of Indian Association of Surgical Oncology

IASO: Prof. M. Vijay Kumar

Dr. Harith Chaturvedi

Prof. B. K. C. Mohan Prasad

Dr. T. Subramaneshwar Rao

Dr. Rajendra S. Toparani

IJSO: Prof. K. S. Gopinath

Prof. Harish K

K. S. Gopinath

gopiijso@gmail.com

1 Bangalore, India 